\title{
A Social-Ecological Approach to Understanding Adolescent Sexting Behavior
}

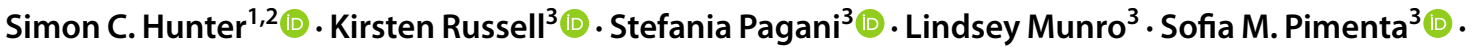 \\ Inmaculada Marín-López ${ }^{4}$ (D) Jun Sung Hong ${ }^{5}$ (D) . Lee Knifton ${ }^{6}$
}

Received: 10 September 2019 / Revised: 11 March 2021 / Accepted: 15 March 2021 / Published online: 12 May 2021

(c) The Author(s) 2021

\begin{abstract}
This study examined the extent to which active and passive sexting behaviors are associated with family-, school-, peer-, and romantic-level variables. Young people $(N=3,322 ; 49.1 \%$ female, $48.3 \%$ male, $2.6 \%$ other $)$ aged 11 to 15 years old $(M=12.84$, $S D=0.89)$ took part, and all attended mainstream secondary schools in Scotland. Participants completed self-report measures of school connectedness, parental love and support, perceived susceptibility to peer- and romantic-pressure (e.g., to display behaviors just to impress others), and their involvement in active and passive sexting. The importance of both school- and family-level factors was evident, though perceived romantic-pressure had the largest effect. However, neither school- nor family-level variables were moderated by either perceived romantic-pressure or perceived peer-pressure. Efforts to reduce sexting or increase its safety should primarily seek to tackle young people's ability to respond effectively to romantic-pressure. It may also be helpful to develop school connectedness and to help families provide support that is constructive and not intrusive.
\end{abstract}

Keywords Sexting $\cdot$ School connectedness $\cdot$ Parenting $\cdot$ Peer-pressure $\cdot$ Romantic-pressure

\section{Introduction}

Sexting refers to sending or receiving of sexually explicit messages or images using the internet or mobile phone (Choi et al., 2016). Adolescents often see sexting as normal behavior (Lippman \& Campbell, 2014; Walker et al., 2013) despite the legal (Lee \& Darcy, 2021; O'Connor et al., 2017), social (Lippman \& Campbell, 2014; Strassberg et al., 2013), and interpersonal (Van Ouytsel et al., 2017) problems that are

Simon C. Hunter

simon.hunter@gcu.ac.uk

1 Department of Psychology, Glasgow Caledonian University, Glasgow G4 0BA, UK

2 Faculty of Education, University of Western Australia, Perth, Australia

3 School of Psychological Sciences and Health, University of Strathclyde, Glasgow, UK

4 Department of Education, University of Córdoba, Córdoba, Spain

5 Department of Adult Health, School of Social Work, Wayne State University, Detroit, MI, USA

6 Dept of Management Science, University of Strathclyde, Glasgow, UK associated with it. To better understand this behavior, it is important to study it within a social-ecological framework that acknowledges the influence of factors at various levels. As outlined below, the decision to engage in sexting is likely to be influenced by competing factors, including variables at the individual, peer, family, and school levels. In this study, we examine the extent to which both active sexting (sending or requesting sexts) and passive sexting (receiving or being asked for sexts) are associated with variables at each level of the social-ecological framework, and whether family- and school-level factors can reduce the negative outcomes associated with peer and romantic interactions.

\section{Sexting}

Sexting is an active behavior involving actions such as asking others to send sexts, sending sexts oneself, or forwarding on sexts. It includes a complex set of behaviors and experiences which differ in the degree to which they are potentially risky. Sexting can also be a passive experience where a young person is the target of sexting behavior, such as, being asked to sext or having unsolicited sexts sent or forwarded to them (Ojeda et al., 2019). 
Recent meta-analyses indicate that $14.8 \%$ of young people (under 18 years old) report sending a sext, $27.4 \%$ have received a sext, and $8.4 \%$ have forwarded a sext without consent (Madigan et al., 2018). Among young adults, aged $18-28$, this increases to $38.3 \%$ who send a sex, $41.5 \%$ who receive a sext, and $47.7 \%$ who engage in reciprocal sexting (Mori et al., 2020). While sexting is associated with both positive and negative emotions (Mitchell et al., 2012; Villacampa, 2017), there is compelling evidence that sexting can be a problematic experience for young people in terms of its associations with risky sexual behavior (e.g., failing to use contraception, having multiple sex partners), delinquent behavior, anxiety/depression, and substance abuse (Mori et al., 2019).

\section{Social-Ecological Framework and Sexting in Young People}

Bronfenbrenner's $(1979,1994)$ ecological systems framework proposes that individual behavior, such as sexting, is influenced by "the ecological environment [which] is conceived as a set of nested structures, each inside the next..." (Bronfenbrenner, 1979, p. 3). The individual is considered to be an inseparable part of multiple, interrelated systems, including the microsystem (i.e., immediate settings such as home or school, e.g., peer relations), mesosystem (i.e., the interrelations among the microsystems, e.g., the relationship between peers and romantic partners), exosystem (i.e., settings which can influence the individual though they are not directly involved in them, such as a parent's workplace), and macrosystem (i.e., cultural or subcultural patterns).

The current study focuses on the microsystem and the mesosystem. These include individual-, peer-, family-, and school-level variables (microsystem), which we will discuss first below. Subsequently, we will also discuss potential interactions between these (mesosystem). Issues relating to peer-pressure are particularly germane for young people since adolescence is a developmental period characterized by increasing independence from adults, allied with the dangers of powerful peer-socialization effects, which are often evident in risky behaviors (Dumas et al., 2012; Kiesner et al., 2002). Young people, particularly males, may pressure their romantic partners into sexting behavior (Lippman \& Campbell, 2014; Martinez-Prather \& Vandiver, 2014; Van Ouytsel et al., 2017; Walker et al., 2013), and pressure from peers more generally can also be associated with more sexting (Lee et al., 2016; Walrave et al., 2014).

Beyond these effects, the extent to which young people identify or connect with their school may also be associated with less sexting. School connectedness is associated with less frequent reports of other risky sexual behaviors (Aspy et al., 2012; Handebo et al., 2018; Shneyderman, \& Schwartz, 2013) as well as lower rates of high-risk or delinquent behaviors, such as smoking and alcohol consumption (Aspy et al., 2012; Azagba \& Asbridge, 2013; Bond et al., 2007; Resnick et al., 1997). Walrave et al. (2014) found that the degree to which young people believe their teachers would approve of them sending sexts, and whether they attached any importance to their teachers' opinions of sexting, did not predict sexting intention among young people. However, to date, no study has examined whether school connectedness is associated with self-reports of sexting behaviors and experiences.

A second contextual school-level variable is the extent to which a school explicitly includes education and support for students surrounding positive interactions. Many U.S. and UK schools are tackling such issues via the Mentors in Violence Prevention (MVP) intervention (Katz, 1995). The MVP program encourages young people to intervene, nonviolently, when they witness violence and challenges their norms around gender-based violence as they work through a "playbook" of scenarios (including one scenario on sharing sexual images of peers). We expect that MVP may reduce sexting rates, predicated upon an understanding of sexting that explicitly includes the abuse of power in a romantic relationship. This is a contentious assertion, given that consenting adults can find sexting to be an enjoyable and positive experience (Burkett, 2015). However, among minors, sexting is usually an illegal activity (O'Connor et al., 2017), and young people, especially girls, can often feel pressured to participate (Lee et al., 2016; Lippman \& Campbell, 2014; Walrave et al., 2014), which suggests that it is often abusive and selfish behavior. In this way, we expect that young people attending schools that participated in the MVP intervention would report lower levels of sexting.

The family is also a salient microsystem for young people, and important attitudes and behaviors are formed in the home, which can then impact the interactions outside of that context (Bronfenbrenner, 1989). Caregivers have their own opinions about sexting and their own ideas about how to tackle it (Fix et al., 2021). Some familial variables are not related to young people's reported intentions to sext, including family living arrangements (Van Ouytsel et al., 2014), parental education (Villacampa, 2017), and parental opinions of sexting (Walrave et al., 2014). However, young people who do not sext do report being more concerned about the consequences of being caught sexting by their parents (Lippman \& Campbell, 2014). Studies to date have not directly considered how the quality of parent-child relationship relates to sexting, yet feeling cared for and loved by one's parents is critical for positive development and psychological adjustment (Sabey et al., 2018) and may be important for this behavior (Lippman \& Campbell, 2014).

In addition to microsystems, it is of theoretical and practical importance to also consider the mesosystem, that is, the ways in which romantic-pressure, peer-pressure, school 
connectedness, and perceived parental love and support may interact and influence each other. This is an important theoretically-informed aspect to study if we want to understand and describe the ways that these operate in young people's lives. In a separate field of research (bullying), scholars have reported interactions between family- and peer-level variables concerning cigarette use, such that higher parental monitoring buffered young people from smoking when they also experienced bullying (Lee et al., 2018). Research also shows that a sense of community can protect young people whose peer and parental influences place them at risk for substance abuse (Mayberry et al., 2009) and that neighborhood socioeconomic status interacts with parenting practices when explaining the likelihood of a young person reporting having had sex (Roche et al., 2005). In the context of sexting, we propose that peer-level variables are likely to moderate any beneficial effects of school- and family-level variables. This is because adolescence is a developmental period characterized by increasing independence from adults and the effects of peer-socialization are evident in risky behaviors (Dumas et al., 2012; Kiesner et al., 2002).

Finally, with respect to the issue of active and passive sexting, these may be differentially associated with the microsystem variables. For example, perceived susceptibility to peerpressure and romantic-pressure, perceived parental love and support, and school connectedness are all likely to be associated with actively sexting. We propose that all four variables will be associated with passive sexting because they are likely to be indicators of the extent to which young people end up in risky situations or risky peer groups where receiving sexts may be more likely. This is based on the assumption that young people who are susceptible to peer-pressure are more likely to belong to deviant or delinquent peer groups (Connolly et al., 2015; Farrell et al., 2017). Similarly, school-level variables and parenting practices can be important determinants of antisocial behavior (Higuita-Gutiérrez \& CardonaArias, 2017; Kramer-Kuhn \& Farrell, 2016; Patterson et al., 1990), and while sexting may be a normative and positive interaction, it also has the potential to be negative and to be associated with more abusive and antisocial behavior (Ojeda et al., 2019).

\section{Research Questions and Hypotheses}

Here, we draw on Bronfenbrenner's $(1979,1994)$ ecological systems framework to assess the relative contributions of peer-pressure, romantic-pressure, school connectedness, and parental love and support in adolescent sexting behavior, an important contribution if we aim to understand young people's behaviors and experiences. Our hypotheses, preregistered on the Open Science Framework (OSF: see Hunter et al., 2019) are: ${ }^{1}$

Hypothesis 1a: School connectedness and parental love and support will both be negatively associated with involvement in active sexting (sending and/or asking for sexts), while perceived peer-pressure and perceived romantic-pressure will both be positively associated with involvement in active sexting.

Hypothesis 1b: Perceived peer-pressure and perceived romantic-pressure will moderate the associations between school connectedness and parental love and support and involvement in active sexting (sending and/or asking for sexts). Specifically, the effects of school connectedness and parental love and support will be weaker when perceived peer-pressure and perceived romantic-pressure are high.

Hypothesis 2: Compared to young people in non-MVP schools, young people attending MVP schools will report less active sexting and less passive sexting.

In addition to these proposed hypotheses, a more exploratory aim was to evaluate Hypotheses $1 \mathrm{a}$ and $1 \mathrm{~b}$ for passive sexting. Finally, following peer review, all analyses were repeated omitting perceived romantic-pressure; this is therefore conducted as an additional exploratory analysis.

\section{Method}

\section{Participants}

A total of 3,322 young people attending 15 mainstream secondary schools in Scotland took part in the survey between Fall 2017 and Spring 2018. The mean age of the participants was 12.84 years $(S D=0.89$, range $11-15)$, of whom 1,631 $(49.1 \%)$ reported their sex as female, 1,606 (48.3\%) as male, and $85(2.6 \%)$ who did not report their sex. The sample predominantly identified as White $(n=3,116 ; 93.8 \%)$, and the remainder identified as Asian, Asian Scottish, or Asian Brit$\operatorname{ish}(n=58 ; 2.6 \%)$, mixed or multiple ethnicity $(n=32 ; 1.4 \%)$, or another ethnic group. Of these, 55\% were from schools participating in MVP, and 45\% were from non-MVP schools. Across Scotland in 2017, 14.1\% of the secondary school students were registered for free school meals (National Statistics, 2017). The schools participating in the current study had a range of $8.9 \%$ to $36.8 \%$ of students eligible for free school meals $(M=17.6 \%, S D=7.02)$. The sample size exceeded the preregistered target sample size ( $N=500$ : Hunter et al., 2019) because of schools' enthusiasm and motivation to take part.

\footnotetext{
${ }^{1}$ Our preregistration on the Open Science Framework includes hypotheses, copies of all measures, relevant data, Mplus code, and other project materials such as participant consent and information sheets.
} 


\section{Measures}

\section{Ethnicity}

Six response options truncated from the Scottish Government's census categories assessed ethnicity: "White," "Asian, Asian Scottish, or Asian British," "mixed or multiple ethnic group," "African," "Caribbean or Black," and "Other ethnic group." These categories were subsequently collapsed into White and non-White for the analysis due to small subsample sizes across each category (ranging from 4 to 58 youths).

\section{Involvement in Sexting}

Choi et al.'s (2016) four-item scale assessing involvement in sexting was used to explore what has the potential to be high-risk sexting behavior, namely images rather than text-only. Participants were asked to respond to the items with reference to "this school year" and responses were either "Yes" or "No." Two scores were created for each participant. The first score represented reports of active sexting behavior and was scaled as 0,1 , or 2 . This reflects whether the young person responded positively to neither, one, or both active sexting items ("Have you asked someone to send naked pictures of them to you?"; "Have you sent naked pictures of yourself to another through text, email, or SnapChat?"). The second score reflected passive sexting experiences and related to the items, "Have you been asked to send naked pictures of yourself through text, email, or things like SnapChat?" and "Has anyone sent you a naked picture without you asking?."

\section{School Connectedness}

The 4-item school connectedness subscale of the Perceived School Experiences Scale (Anderson-Butcher et al., 2012) was used (e.g., "I feel like I belong to my school"). Possible responses were $1=$ "strongly disagree," $2=$ "disagree," $3=$ "neither agree nor disagree," $4=$ =agree," and $5=$ "strongly agree." A mean score was created from the responses to these items where higher scores indicated greater school connectedness. Internal reliability for this scale was satisfactory $(\alpha=0.79)$.

\section{Parental Love and Support}

Parental love and support was assessed with a 6-item scale used by Merrin et al. (2015). This scale utilized a 4-point scale $(0=$ "Never" to $3=$ "Always"). An example item is "My parents/guardians...encourage me to do well." A mean score was created, and higher scores reflect higher parental love and support. Internal reliability for this scale was satisfactory $(\alpha=0.75)$.

\section{Perceived Susceptibility to Peer-Pressure}

Perceived susceptibility to peer-pressure was measured using the four items in Williams and Anthony's (2015) study. An example item is "I tend to go along with the crowd," and the response options were "Not like me," "A little like me," or "A lot like me." Responses were scored so that a higher score reflected higher perceived susceptibility to peer-pressure. A mean score was created from responses to these items. Internal reliability for this scale was adequate $(\alpha=0.63)$.

\section{Perceived Susceptibility to Romantic-Pressure}

Perceived susceptibility to romantic-pressure was assessed using an adapted version of Williams and Anthony's (2015) scale. This measure was adapted to refer specifically to the romantic relationship context: "I do things just to be popular with my partner"; "I let my partner talk me into doing things I don't really want to do"; "I try hard to impress my partner"; and "I tend to go along with the things my partner wants to do." Response options were "Not like me," "A little like me," and "A lot like me," which were scored in the same way as for peer-pressure. A mean score was used where higher scores indicated greater perceived susceptibility to romanticpressure. Internal reliability for this scale was satisfactory $(\alpha=0.74)$.

\section{Procedure}

Ethical approval for the project was obtained from the second author's institution. In Scotland, young people aged 12 and over can give their own consent to participate in if they are considered able to do so (e.g., not having a specific vulnerability such as mental or physical illness). However, given the potentially controversial nature of the questions included in this study (regarding sexting), we gave parents the opportunity to withdraw their child from participation. Approval was obtained from seven Local Education Authorities to contact schools to request their participation. Of those schools that were approached, 15 (32\%) agreed to take part. This is consistent with previous research taking place in secondary schools in Scotland (see O'Connor et al., 2009; Russell et al., 2018). Schools were targeted based on their MVP status (engaged or not engaged with MVP).

The aim of the study was explained to school gatekeepers (e.g., Principals). Parents were informed of the project by letter and asked to notify the school or research team if they did not want their child to participate. Young people were then invited to participate in the study. Respondents completed the 
self-report surveys anonymously using paper-based copies (to allow, for example, covering of answers) and completed these independently within a classroom or assembly hall setting. Teachers and members of the research team made themselves available at all times to answer any questions that the students had regarding the survey procedure or content. All participants were debriefed and provided with information as to where they could seek support if they were concerned about bullying or sexting. All letters and information sheets used in the project are openly available in the preregistration for this project (Hunter et al., 2019).

\section{Analytic Plan}

The data were analyzed using Mplus Version 7.31 (Muthén \& Muthén, 1998-2012). Mplus allows missing data to be addressed using Full Information Maximum Likelihood (FIML). All main analyses were based on a subsample of the data $(n=2,253)$ : The sex of the participants was treated as a binary variable with all respondents who chose "Prefer not to say" excluded due to the low frequency of such responses $(n=85)$. Additionally, survey instructions required participants to leave the perceived susceptibility to romanticpressure items blank if they had never had a boyfriend or girlfriend, and 984 participants who did so were also therefore excluded. The Cronbach's alphas for scale reliabilities reported above were calculated on this subsample.

The analyses differed slightly from the preregistration for this study. There was a clear repetition of the analyses across models and so a slightly more efficient analytic approach was used. Specifically, the effect of MVP/non-MVP school status on active and passive sexting was originally proposed to be assessed in one model (see the preregistered analysis for Hypothesis 2), and a separate model was planned to assess the effects of other study variables on active sexting (see the preregistered analysis for Hypothesis 1a). The evaluation of the MVP/non-MVP distinction was therefore included in the same analysis that assessed Hypothesis 1 so that its effects could be examined in the same model as other effects. In addition, the examination of the effects of study variables on passive sexting was not preregistered. Since active sexting and passive sexting were significantly correlated $[r$ $(\mathrm{df}=2251)=0.34, p<.001]$, both forms of sexting were included as outcome variables in the same models rather than being estimated separately. Finally, when estimating the models assessing the possibility of the interactions, the MLR estimator was not used because bootstrapping was employed (precluding the use of the MLR estimator). Instead, the ML estimator is used, and we note that bootstrapping procedures also address non-normality in data.

Thus, we ran one analysis where both forms of sexting were regressed on school connectedness, parental love and support, perceived peer-pressure, perceived romantic-pressure, and MVP/Non-MVP status. Covariates were age, sex, and ethnicity. Descriptive statistics were calculated using SPSS version 25 . Following this, we evaluated one model per possible interaction: (a) Perceived susceptibility to peer-pressure $\times$ School connectedness; (b) Perceived susceptibility to peer-pressure $\times$ Parental love and support; (c) perceived susceptibility to romantic-pressure $\times$ School connectedness; (d) perceived susceptibility to romantic-pressure $\times$ Parental love and support). Thus, four models were estimated in total to assess the interaction terms. This approach (conducting four separate analyses) was preregistered as the inclusion of multiple interaction terms sharing the same variables would be highly likely to result in difficulties with multicollinearity. The variables included in each interaction (e.g., perceived susceptibility to peer-pressure $\times$ school connectedness) were also included as predictors, and the two variables (e.g., perceived susceptibility to romantic-pressure and parental love and support) not contained in the interaction were included as covariates. The variables included in each interaction were mean-centered. In each model, covariates also included age, sex, ethnicity, and MVP/non-MVP status. Given the number of estimated parameters across all models, alpha was set at a $1 \%$ level rather than $5 \%$. All code is hosted on the Open Science Framework (Hunter et al., 2019).

To explore significant interactions, it was preregistered that moderation procedures be implemented in Mplus (based on the code produced by Stride et al., 2015). However, no interaction terms were significant (all $p>.107$ ), and therefore, this was not required.

The main analyses were all repeated omitting perceived susceptibility to romantic-pressure. This was an exploratory set of analyses, and since they did not require that young people be in romantic relationships, we included the full data set.

\section{Results}

Descriptive statistics are shown in Table 1. Active sexting was significantly correlated with all main study variables. The correlation with MVP status was small and was only significant at the 5\% level. Passive sexting was significantly correlated with all main study variables except MVP status. The four main study variables were all significantly correlated with each other, most notably, school connectedness and parental love and support $(r[2181]=0.35, p<.001)$ and both forms of perceived pressure $(r[2235]=0.49, p<.001)$.

The first analysis, involving no interaction terms, accounted for $18 \%$ of the variance in passive sexting and $6 \%$ of the variance in active sexting $\left(R^{2}=0.180\right.$ and 0.064 , respectively). The results are summarized in Table 2.

Ethnic group status was not associated with sexting. Girls reported more passive sexting than boys $(41.8 \%$ vs $24.3 \%$ ) but did not differ on reports of active sexting. Age 
Table 1 Descriptive statistics for, and correlations between, all main study variables and covariates

\begin{tabular}{|c|c|c|c|c|c|c|c|c|c|c|c|}
\hline Variable & 2 & 3 & 4 & 5 & 6 & 7 & 8 & 9 & 10 & $M(\mathrm{SD})$ or $\%$ & Range \\
\hline 1. Active sexting & $.34 * * *$ & $.15 * * *$ & -.01 & -.02 & $.05^{*}$ & $-.11 * * *$ & $-.12 * * *$ & $.11 * * *$ & $.16^{* * *}$ & $0.08(0.33)$ & $0-2$ \\
\hline 2. Passive sexting & - & $.21 * * *$ & $.21 * * *$ & -.03 & .03 & $-.19 * * *$ & $-.15 * * *$ & $.12 * * *$ & $.18^{* * *}$ & $0.51(0.78)$ & $0-2$ \\
\hline 3. Age & - & - & -.02 & .01 & $.05^{*}$ & $-.11 * * *$ & $-.04 *$ & -.01 & $.06^{* *}$ & $12.89(0.89)$ & $11-15$ \\
\hline 4. $\operatorname{Sex}^{\mathrm{a}}$ & - & - & - & $-.07 * *$ & -.00 & $.08 * * *$ & $.08 * *$ & $.12 * * *$ & $-.20 * * *$ & $51.0 \%$ Male & - \\
\hline 5. Ethnicity ${ }^{\mathrm{b}}$ & - & - & - & - & -.01 & .00 & -.03 & .04 & .03 & 95.0\% White & - \\
\hline 6. MVP status ${ }^{\mathrm{c}}$ & - & - & - & - & - & .03 & $.06 * *$ & .00 & -.01 & $56.9 \%$ MVP & - \\
\hline 7. SC & - & - & - & - & - & - & $.35 * * *$ & $-.11 * * *$ & $-.10 * * *$ & $3.52(0.77)$ & $0.5-5$ \\
\hline 8. PLS & - & - & - & - & - & - & - & $-.12 * * *$ & $-.10 * * *$ & $2.28(0.56)$ & $0-4$ \\
\hline 9. PPP & - & - & - & - & - & - & - & - & $.49 * * *$ & $0.46(0.42)$ & $0-2$ \\
\hline 10. PRP & - & - & - & - & - & - & - & - & - & $0.32(0.41)$ & $0-2$ \\
\hline
\end{tabular}

Note. $\mathrm{SC}=$ school connectedness; $\mathrm{PLS}=$ parental love and support $\mathrm{PPP}=$ perceived susceptibility to peer-pressure; $\mathrm{PRP}=$ perceived susceptibility to romantic-pressure. Due to missing data, sample sizes across analyses ranged from 2,207 to 2,253

${ }^{\text {a }}$ Sex is coded as $1=$ Boy, $2=$ Girl

${ }^{\mathrm{b}}$ Ethnicity is coded as $1=$ White, $2=$ Not White

${ }^{\mathrm{c}} \mathrm{MVP}$ status is coded as $0=$ Non-MVP, $1=$ MVP

${ }^{*} p<.05$. ** $p<.01 . * * * p<.001$

Table 2 Model results predicting active and passive sexting

\begin{tabular}{|c|c|c|c|c|c|c|c|c|}
\hline \multirow[t]{2}{*}{ Variable } & \multicolumn{4}{|l|}{ Passive sexting } & \multicolumn{4}{|l|}{ Active sexting } \\
\hline & $\mathrm{b}(\mathrm{SE})$ & $95 \% \mathrm{CI}$ & Sig & $\beta^{l}$ & $\mathrm{~b}(\mathrm{SE})$ & $95 \% \mathrm{CI}$ & Sig & $\beta^{a}$ \\
\hline Age & $0.17(0.02)$ & $0.13,0.20$ & $<.001$ & .19 & $0.05(0.01)$ & $0.03,0.07$ & $<.001$ & .13 \\
\hline $\operatorname{Sex}^{b}$ & $0.43(0.03)$ & $0.37,0.49$ & $<.001$ & .28 & $0.03(0.01)$ & $-0.00,0.05$ & .070 & .04 \\
\hline Ethnicity $^{\mathrm{c}}$ & $-0.05(0.07)$ & $-0.18,0.08$ & .418 & -.02 & $-0.03(0.02)$ & $-0.07,0.02$ & .197 & -.02 \\
\hline MVP status ${ }^{\mathrm{d}}$ & $0.05(0.03)$ & $-0.01,0.11$ & .087 & .03 & $0.04(0.01)$ & $0.01,0.06$ & .009 & .05 \\
\hline $\mathrm{SC}$ & $-0.14(0.02)$ & $-0.18,-0.10$ & $<.001$ & -.14 & $-0.02(0.01)$ & $-0.04,-0.00$ & .040 & -.05 \\
\hline PLS & $-0.13(0.03)$ & $-0.19,-0.07$ & $<.001$ & -.09 & $-0.05(0.02)$ & $-0.08,-0.02$ & .003 & -.08 \\
\hline PPP & $0.07(0.04)$ & $-0.01,0.15$ & .096 & .04 & $0.03(0.02)$ & $-0.01,0.08$ & .206 & .04 \\
\hline PRP & $0.35(0.05)$ & $0.27,0.43$ & $<.001$ & .19 & $0.11(0.03)$ & $0.06,0.16$ & $<.001$ & .13 \\
\hline SCXPPP & $0.06(0.04)$ & $--0.02,0.14$ & .188 & .03 & $0.05(0.03)$ & $-0.01,0.11$ & .107 & .05 \\
\hline SCXPRP & $-0.05(0.04)$ & $-0.13,0.03$ & .266 & -.02 & $0.01(0.03)$ & $-0.05,0.08$ & .672 & .02 \\
\hline PLSxPPP & $-0.04(0.06)$ & $-0.16,0.09$ & .563 & -.01 & $0.03(0.05)$ & $-0.06,0.12$ & .537 & .02 \\
\hline PLSxPRP & $-0.02(0.06)$ & $-0.15,0.08$ & .564 & -.01 & $0.02(0.05)$ & $-0.06,0.11$ & .606 & .02 \\
\hline
\end{tabular}

Note $. \mathrm{SC}=$ school connectedness; $\mathrm{PLS}=$ parental love and support $\mathrm{PPP}=$ perceived susceptibility to peerpressure; $\mathrm{PRP}=$ perceived susceptibility to romantic-pressure

${ }^{a}$ STDYX standardized results are reported

${ }^{\mathrm{b}} \mathrm{Sex}$ is coded as $1=$ Boy, $2=$ Girl

${ }^{c}$ Ethnicity is coded as $1=$ White, $2=$ Not White

${ }^{\mathrm{d}}$ MVP status coded $0=$ Non-MVP, $1=$ MVP was significantly and positively associated with both forms of sexting. Active sexting was uncommon among 11- and 12 -year-olds (1.1\% and $1.8 \%$, respectively) but became more frequent among 13- and 14-year-olds (5.6\% and $11.1 \%$, respectively). Passive sexting experiences also became steadily more frequent as the participants got older, as reported by $16.7 \%$ of the 11 -year-olds, $20.6 \%$ of 12 -year-olds, $36.4 \%$ of 13 -year-olds, and $45.3 \%$ of 14 -year-olds.
We found mixed support for Hypothesis 1a. School connectedness was significantly and negatively associated with passive sexting but was not associated with active sexting. This was the only difference between the two forms of sexting when considering the four main study variables, and it was contrary to our expectation that effects would be stronger for active than for passive sexting. Parental love and support was negatively associated with both passive sexting and active sexting. Perceived susceptibility to peer-pressure was not 
associated with either form of sexting, but perceived susceptibility to romantic-pressure was positively associated with reports of both passive sexting and active sexting. Finally, active sexting was higher among young people attending MVP schools than those not attending MVP schools, but this was not the case for passive sexting. Young people in MVP schools reported a higher prevalence of active sexting (6.9\%) than those not in MVP schools (4.2\%), contradicting Hypothesis 2.

Finally, none of the four interactions were significant (all $p s \geq 0.150$ ) (see Table 2), thus failing to support Hypothesis $1 b$. This indicates that the school- and parent-level variables did not buffer young people against any negative effects of perceived peer- or romantic-pressure.

\section{Exploratory Analyses}

When running the models without including perceived susceptibility to romantic-pressure (and hence including all participants), there were two main differences. First, in the model, which did not include the interaction terms, the pattern of results was largely similar in terms of significance and sizes of effects except that (a) MVP and non-MVP schools did not differ on active sexting $(\mathrm{b}=0.02, \mathrm{SE}=0.01, p=.046$, $\beta=0.03$ ), and (b) perceived susceptibility to peer-pressure was a significant predictor of both active $(b=0.07, \mathrm{SE}=0.02$, $p<.001, \beta=0.10)$ and passive $(\mathrm{b}=0.23, \mathrm{SE}=0.03, p<.001$, $\beta=0.13$ ) sexting.

The interaction term perceived susceptibility to peerpressure $\times$ school connectedness was not significant for either active $(\mathrm{b}=0.03, \mathrm{SE}=0.02, p=.253, \beta=0.03)$ or passive $(\mathrm{b}=0.01, \mathrm{SE}=0.04, p=.699, \beta=0.01)$ sexting. The same was true with regard to the interaction term perceived susceptibility to peer-pressure $\times$ parental love and support, which was not significant for either active $(b=0.02, \mathrm{SE}=0.04$, $p=.681, \beta=0.01)$ or passive $(\mathrm{b}=0.05, \mathrm{SE}=0.05, p=.323$, $\beta=0.02$ ) sexting.

\section{Discussion}

Sexting is a relatively common experience for young people and is associated with both positive and negative outcomes (e.g., Medrano et al., 2018; Mitchell et al., 2012). To our surprise, efforts to understand these experiences and behaviors using multiple-level variables drawn from different areas of the social-ecological framework (Bronfenbrenner, 1979) are absent from the research literature. This study extends previous work by considering whether school, family, and interpersonal variables (microsystem), and specific interactions between these (mesosystem) can help researchers and practitioners to better understand both active sexting behaviors and passive sexting experiences during adolescence. In our main analyses, there was no evidence that school- or familylevel variables interacted with perceptions of susceptibility to peer- and/or romantic-pressure in reports of sexting behavior. There were main effects of parental love and support on both active and passive sexting, and the same for perceived susceptibility to romantic-pressure. However, there were no unique effects of perceived susceptibility to peer-pressure, and school connectedness was associated with passive, but not active sexting. Finally, young people who were attending schools engaging with the MVP intervention reported higher rates of active sexting. Exploratory analyses revealed that perceived susceptibility to peer-pressure was significant when perceived susceptibility to romantic-pressure was omitted from the statistical models, highlighting its importance outside of romantic relationships.

School connectedness was significantly and negatively associated with passive sexting but was not associated with active sexting. Using school-based interventions (Centers for Disease Control and Prevention, 2009; King et al., 2002), school connectedness can be improved, and the results presented here suggest that such interventions may help reduce the extent to which young people are asked to send sexts and have unsolicited sexts sent to them. However, our results provide less support for the possibility that improvements in school connectedness could reduce more active sexting behaviors (e.g., sending sexts).

The second school-level factor, whether young people were attending MVP schools or not, was associated with active sexting but not with passive sexting. Contrary to what was expected, young people in MVP schools reported a higher prevalence of active sexting than those not in MVP schools. No previous studies have specifically examined sexting in the context of the MVP intervention, and it is important to note that the nature of the present study precludes the interpretation that the intervention increases such behavior. For example, it may be that young people in MVP schools engaged in more sexting prior to taking part in the intervention. A more complex research design (e.g., a randomized controlled trial) is required to begin to untangle such effects. For now, though, it is interesting to note that the two schoollevel factors assessed in this study were associated with different forms of sexting. This may be evidence that it is important to carefully consider the nature of any intervention when seeking to influence different forms of sexting.

There were interesting differences concerning young people's perceived susceptibility to different forms of pressure, and in how these related to their reports of sexting. There were significant, positive bivariate correlations between both forms of sexting and both peer- and romantic-pressure, but in the main analyses, the effect of perceived peer-pressure was not significant. This suggests that any association of sexting with general peer-pressure may be unimportant compared to the pressure within a romantic relationship. At the same time, 
the results of our exploratory analyses, which did not include perceived susceptibility to romantic-pressure, remind us of the importance of considering peer-pressure more generally, especially since not all sexting will necessarily take place within a romantic relationship. During adolescence, young people learn how to navigate romantic interactions, and this can involve learning about issues such as showing respect, making sacrifices, being assertive, and building trust (Dmytro et al., 2013). Additionally, the digital world is another contextual condition that young people need to consider (Cameron et al., 2017). The current findings suggest that learning how to cope with romantic-pressures surrounding sexting may be a salient part of this digital contextualization of relationships and their progression. Helping young people to make informed and responsible choices about sharing intensely personal thoughts, opinions, or images should therefore include ways in which they can effectively and sensitively manage and respond to partners' sexting advances.

Finally, parental love and support was negatively related to both active and passive sexting. This extends previous research by looking at young people's reports of both engaging in, and experiencing sexting. Importantly, this highlights the important role that families can play in shaping the ways in which young people use technology in romantic relationships. It is notable here that the items employed in our study to assess parental love and support reflected the presence of clear rules, encouragement, and expressing interest and support in their future plans. This form of supportive parenting may encourage young people to take control of their own lives and to be more assertive when sexting arises in interpersonal relationships. Notably, this type of parenting may contrast sharply with parenting that is over-bearing or perceived to be intrusive as this latter parenting (in the form of monitoring phones for sexting activity) seems to be unrelated to levels of sexting (Martinez-Prather \& Vandiver, 2014). A qualitative approach to understanding the role of families in sexting could helpfully explore such issues.

Overall, there was only partial support for Hypothesis $1 \mathrm{a}$. With regard to Hypothesis 1b, in which school- and family-level variables were hypothesized to interact with peerpressure variables, there was no support, as no interactions were significant (even in the context of our relatively large sample size). This argues against the notion of a mesosystem (interaction between microsystems) operating with respect to sexting, at least with regard to the variables and interactions assessed here. This has implications for intervention strategies because it suggests that the effects of both school connection and of parental love and support are independent of perceived romantic-pressure. In such a context, it is important to develop multi-stranded interventions that aim to address multiple factors associated with sexting: romantic- and peer-pressure, school connectedness, and parental love and support.
This study has a number of strengths, including the large sample size, examination of the multiple microsystem factors simultaneously, and the investigation of the mesosystem. However, it is important to also note that the cross-sectional design of the current study precludes any causal inferences concerning the impact of microsystem variables on sexting. Thus, for example, the MVP program may be associated with higher levels of active sexting because such differences may partly drive schools to enlist in a gender-based violence intervention, to begin with. The most rigorous way to assess the impact of the intervention is to use pre- and post-assessments, with control schools, and to randomly allocate all schools to control or treatment conditions, but this was outside the scope and remit of the current study. The reliance on self-report measures may also be a weakness of the current study since it potentially leads to shared-method variance, though the extent to which this is a problem is contentious and different variables and measures can impact how much variance is shared (Richardson et al., 2009).

Past research has varied in whether reports of sexting differed according to young people's sex. Among the young people in the current study, girls reported more involvement in passive sexting, but there was no difference between boys and girls in terms of active sexting. Taken together with the mixed reports in the research literature concerning any such difference and the direction of it (Lippman \& Campbell, 2014; Marcum et al., 2014; Martinez-Prather \& Vandiver, 2014; Mitchell et al., 2012; Morelli et al., 2016; Strassberg et al., 2013; Van Ouytsel et al., 2014), this may suggest that it is important to consider the form that sexting takes if seeking to understand and intervene in episodes of adolescent sexting. The nature of the items we used to assess passive sexting, combined with our results concerning perceived susceptibility to romantic-pressure, suggests that it may be particularly important to support girls and young women to be comfortable and confident should they wish to rebuff unwanted requests for sexts (or indeed unwanted sexts) from their romantic partners.

\section{Conclusions}

This study is the first to examine the associations of sexting experiences and behaviors with multiple variables drawn from the social-ecological framework (Bronfenbrenner, 1979). The importance of both school- and family-level factors in the context of young people's sexting interactions was evident, though perceived romantic-pressure had the largest effect. Neither school- nor family-level variables reduced the effect associated with perceived romantic-pressure. Future intervention efforts should primarily seek to tackle young people's ability to respond effectively to romantic-pressure within romantic relationships and more general peer-pressure outside of these. They may also benefit from efforts to 
encourage school connectedness and to help families provide the support that is constructive and not intrusive.

Acknowledgements We would like to extend thanks to all the Local Education Authorities, schools, staff, and young people who so enthusiastically took part in this study. We would also like to thank Abbey McNeil, Belle Manning, Ashley Anderson, Doriana De Gradi, Rachael Lytton, Hollie Philip, Kizzy Shepherd, Amy MacPherson, Andrew Robertson, and Ryan Barbour for their help and support processing data for the project.

Author Contributions SCH, LK, and KR contributed to the study conception and design. Material preparation, data collection, and analysis were performed by KR, SP, LM, SP, and IML. The first draft of the article was written by SCH and JSH, and all authors commented on previous versions of the article. All authors read and approved the final article and subsequent revisions.

Funding This research was supported by Police Scotland's Violence Reduction Unit. The sponsor had no role to play in study design; in the collection, analysis and interpretation of data; nor in the writing of the report. A final version of the article was passed to the sponsor prior to submission, and no changes or concerns were raised at that point.

\section{Declarations}

Conflict of interest Kirsten Russell works at the Violence Reduction Unit (the funder), taking up that post after the project was completed; she did not work for the Violence Reduction Unit at the time this work was undertaken or when this article was first drafted.

Ethical Approval All procedures performed in studies involving human participants were in accordance with the ethical standards of the institutional research committee.

Informed Consent Informed consent was obtained from all individual participants included in the study.

Open Access This article is licensed under a Creative Commons Attribution 4.0 International License, which permits use, sharing, adaptation, distribution and reproduction in any medium or format, as long as you give appropriate credit to the original author(s) and the source, provide a link to the Creative Commons licence, and indicate if changes were made. The images or other third party material in this article are included in the article's Creative Commons licence, unless indicated otherwise in a credit line to the material. If material is not included in the article's Creative Commons licence and your intended use is not permitted by statutory regulation or exceeds the permitted use, you will need to obtain permission directly from the copyright holder. To view a copy of this licence, visit http://creativecommons.org/licenses/by/4.0/.

\section{References}

Anderson-Butcher, D., Amorose, A., Iachini, A., \& Ball, A. (2012). The development of the perceived school experiences scale. Research on Social Work Practice, 22(2), 186-194. https://doi.org/10.1177/ 1049731511419866

Aspy, C. B., Vesely, S. K., Oman, R. F., Tolma, E., Rodine, S., Marshall, L., \& Fluhr, J. (2012). School-related assets and youth risk behaviors: Alcohol consumption and sexual activity. Journal of
School Health, 82(1), 3-10. https://doi.org/10.1111/j.1746-1561. 2011.00661.x.

Azagba, S., \& Asbridge, M. (2013). School connectedness and susceptibility to smoking among adolescents in Canada. Nicotine and Tobacco Research, 15(8), 1458-1463. https://doi.org/10.1093/ ntr/nts340.

Bond, L., Butler, H., Thomas, L., Carlin, J., Glover, S., Bowes, G., \& Patton, G. (2007). Social and school connectedness in early secondary school as predictors of late teenage substance use, mental health, and academic outcomes. Journal of Adolescent Health, 40(4), 357.e9-357.e18. https://doi.org/10.1016/j.jadohealth.2006. 10.013 .

Bronfenbrenner, U. (1979). The ecology of human development: Experiments by nature and design. Harvard University Press.

Bronfenbrenner, U. (1989). Ecological systems theory. In R. Vasta (Ed.), Annals of child development (Vol. 6): Six theories of child development: Revised formulations and current issues (pp. 187-249). JAI Press.

Bronfenbrenner, U. (1994). Ecological models of human development. In T. Husen \& T. N. Postlethwaite (Eds.), International encyclopedia of education (Vol. 3, 2nd ed., pp. 1643-1647). Oxford, UK: Pergamon Press/Elsevier Science.

Burkett, M. (2015). Sex (t) talk: A qualitative analysis of young adults' negotiations of the pleasures and perils of sexting. Sexuality and Culture, 19(4), 835-863. https://doi.org/10.1007/ s12119-015-9295-0.

Cameron, A., Luft, T., Dmytro, D., Kubiliene, N., \& Chou, W. (2017). Adolescents negotiating romantic relationships in a culturally diverse, urban community. International Journal of Child, Youth and Family Studies, 8(1), 1-19. https://doi.org/10.18357/ijcyf s81201716739.

Centers for Disease Control and Prevention. (2009). School connectedness: Strategies for increasing protective factors among youth. Atlanta, GA: U.S. Department of Health and Human Services. Retrieved from https://www.cdc.gov/healthyyouth/protective/pdf/ connectedness.pdf.

Choi, H., Van Ouytsel, J., \& Temple, J. R. (2016). Association between sexting and sexual coercion among female adolescents. Journal of Adolescence, 53, 164-169. https://doi.org/10.1016/j.adolescence. 2016.10.005.

Connolly, E. J., Schwartz, J. A., Nedelec, J. L., Beaver, K. M., \& Barnes, J. C. (2015). Different slopes for different folks: Genetic influences on growth in delinquent peer association and delinquency during adolescence. Journal of Youth and Adolescence, 44(7), 1413-1427. https://doi.org/10.1007/s10964-015-0299-8.

Dmytro, D., Luft, T., Jenkins, M., Hoard, R., \& Cameron, C. A. (2013). Rural adolescent boys' negotiating heterosexual romantic relationships: "We need to sacrifice our brains." Canadian Journal of Counselling and Psychotherapy, 47(3), 361-382.

Dumas, T. M., Ellis, W. E., \& Wolfe, D. A. (2012). Identity development as a buffer of adolescent risk behaviors in the context of peer group pressure and control. Journal of Adolescence, 35(4), 917-927. https://doi.org/10.1016/j.adolescence.2011.12.012.

Farrell, A. D., Thompson, E. L., \& Mehari, K. R. (2017). Dimensions of peer influences and their relationship to adolescents' aggression, other problem behaviors and prosocial behavior. Journal of Youth and Adolescence, 46(6), 1351-1369. https://doi.org/10. 1007/s10964-016-0601-4.

Fix, R. L., Assini-Meytin, L. C., Harris, A. J., \& Letourneau, E. J. (2021). Caregivers' perceptions and responses to a new norm: The missing link in addressing adolescent sexting behaviors in the U.S. Archives of Sexual Behavior, 50, 575-588. https://doi.org/10.1007/ s10508-020-01704-z.

Handebo, S., Kebede, Y., \& Morankar, S. N. (2018). Does social connectedness influence risky sexual behaviours? Finding from 
Ethiopian youths. International Journal of Adolescence and Youth, 23(2), 145-158. https://doi.org/10.1080/02673843.2017.1306448.

Higuita-Gutiérrez, L. F., \& Cardona-Arias, J. A. (2017). Variables of the family, school, and social environment context that determine bullying in adolescents in Medellín, Colombia, 2014. Journal of School Violence, 16(1), 68-85. https://doi.org/10.1080/15388220. 2015.1112807.

Hunter, S. C., Russell, Ki., Pagani, S., Munro, L., Marín-López, I., Knifton, L., \& Hong, J. S. (2019). Individual, family, and school factors relating to sexting and bullying. https://doi.org/10.17605/ OSF.IO/2EVG4.

Katz, J. (1995). Reconstructing masculinity in the locker room: The Mentors in Violence Prevention Project. Harvard Educational Review, 65, 163-175. https://doi.org/10.17763/haer.65.2.55533 $188520136 u 1$

Kiesner, J., Cadinu, M., Poulin, F., \& Bucci, M. (2002). Group identification in early adolescence: Its relation with peer adjustment and its moderator effect on peer influence. Child Development, 73(1), 196-208. https://doi.org/10.1111/1467-8624.00400.

King, K. A., Vidourek, R. A., Davis, B., \& McClellan, W. (2002). Increasing self-esteem and school connectedness through a multidimensional mentoring program. Journal of School Health, 72(7), 294-299. https://doi.org/10.1111/j.1746-1561.2002.tb013 36.x.

Kramer-Kuhn, A. M., \& Farrell, A. D. (2016). The promotive and protective effects of family factors in the context of peer and community risks for aggression. Journal of Youth and Adolescence, 45(4), 793-811. https://doi.org/10.1007/s10964-016-0438-x.

Lee, J. R., \& Darcy, K. M. (2021). Sexting: What's law got to do with it? Archives of Sexual Behavor, 50, 563-573. https://doi.org/10. 1007/s10508-020-01727-6.

Lee, J., Hong, J. S., Resko, S. M., \& Tripodi, S. J. (2018). Face-toface bullying, cyberbullying, and multiple forms of substance use among school-age adolescents in the USA. School Mental Health, 10(1), 12-25. https://doi.org/10.1007/s12310-017-9231-6.

Lee, C. H., Moak, S., \& Walker, J. T. (2016). Effects of self-control, social control and social learning on sexting behaviour among South Korean youths. Youth and Society, 48(2), 242-264. https:// doi.org/10.1177/0044118X13490762.

Lippman, J. R., \& Campbell, S. W. (2014). Damned if you do, damned if you don't...If you're a girl: Relational and normative contexts of adolescent sexting in the United States. Journal of Children and Media, 8(4), 371-386. https://doi.org/10.1080/17482798. 2014.923009.

Madigan, S., Ly, A., Rash, C. L., Van Ouytsel, J., \& Temple, J. R. (2018). Prevalence of multiple forms of sexting behavior among youth: A systematic review and meta-analysis. JAMA Pediatrics, 172(4), 327-335. https://doi.org/10.1001/jamapediatrics.2017. 5314.

Marcum, C. D., Higgins, G. E., \& Ricketts, M. L. (2014). Sexting behaviour among adolescents in rural North Carolina: A theoretical examination of low self-control and deviant peer association. International Journal of Cyber Criminology, 5(2), 55-78.

Martinez-Prather, K., \& Vandiver, D. M. (2014). Sexting among teenagers in the US: A retrospective analysis of identifying motivating factors, potential targets and the role of a capable guardian. International Journal of Cyber Criminology, 8(1), 21-35.

Mayberry, M. L., Espelage, D. L., \& Koenig, B. (2009). Multilevel modeling of direct effects and interactions of peers, parents, school, and community influences on adolescent substance use. Journal of Youth and Adolescence, 38(8), 1038-1049. https://doi.org/10. 1007/s10964-009-9425-9.

Medrano, J. L. J., Lopez Rosales, F., \& Gámez-Guadix, M. (2018). Assessing the links of sexting, cybervictimization, depression, and suicidal ideation among university students. Archives of Suicide
Research, 22(1), 153-164. https://doi.org/10.1080/13811118. 2017.1304304.

Merrin, G. J., Hong, J. S., \& Espelage, D. L. (2015). Are the risk and protective factors similar for gang-involved, pressured-to-join, and non-gang-involved youth? A social-ecological analysis. American Journal of Orthopsychiatry, 85(6), 522. https://doi.org/10.1037/ ort0000094.

Mitchell, K. J., Finkelhor, D., Jones, L. M., \& Wolak, J. (2012). Prevalence and characteristics of youth sexting: A national study. Pediatrics, 129(1), 13-20. https://doi.org/10.1542/peds.2011-1730.

Morelli, M., Bianchi, D., Baiocco, R., Pezzuti, L., \& Chirumbolo, A. (2016). Sexting, psychological distress and dating violence among adolescents and young adults. Psicothema, 28(2), 137-142. https:// doi.org/10.7334/psicothema2015.193.

Mori, C., Cooke, J. E., Temple, J. R., Ly, A., Lu, Y., Anderson, N., Rash, C., \& Madigan, S. (2020). The prevalence of sexting behaviors among emerging adults: A meta-analysis. Archives of Sexual Behavior, 49, 1103-1119. https://doi.org/10.1007/ s10508-020-01656-4.

Mori, C., Temple, J. R., Browne, D., \& Madigan, S. (2019). Association of sexting with sexual behaviors and mental health among adolescents: A systematic review and meta-analysis. JAMA Pediatrics, 173(8), 770-779. https://doi.org/10.1001/jamapediatrics. 2019.1658.

Muthén, L. K., \& Muthén, B. O. (1998-2012). Mplus user's guide (Seventh ed.). Los Angeles, CA.

National Statistics. (2017). Summary statistics for attainment, leaver destinations and healthy living No. 7. (2017th ed.). Scottish Government.

O'Connor, K., Drouin, M., Yergens, N., \& Newsham, G. (2017). Sexting legislation in the United States and abroad: A call for uniformity. International Journal of Cyber Criminology, 11(2), 218-245. https://doi.org/10.5281/zenodo.1037397.

O’Connor, R. C., Rasmussen, S., Miles, J., \& Hawton, K. (2009). Selfharm in adolescents: Self-report survey in schools in Scotland. The British Journal of Psychiatry, 194(1), 68-72. https://doi.org/10. 1192/bjp.bp.107.047704.

Ojeda, M., Del Rey, R., \& Hunter, S. C. (2019). Longitudinal relationships between sexting and involvement in both bullying and cyberbullying. Journal of Adolescence, 77, 81-89. https://doi.org/ 10.1016/j.adolescence.2019.10.003.

Patterson, G. R., DeBaryshe, B., \& Ramsey, E. (1990). A developmental perspective on antisocial behaviour. American Psychologist, 44, 329-335. https://doi.org/10.1037//0003-066x.44.2.329.

Resnick, M. D., Bearman, P. S., Blum, R. W., Bauman, K. E., Harris, K. M., Jones, J., Tabor, J., Beuhring, T., Sieving, R. E., Shew, M., Ireland, M., Bearinger, L. H., \& Udry, J. R. (1997). Protecting adolescents from harm: Findings from the National Longitudinal Study on Adolescent Health. Journal of the American Medical Association, 278(10), 823-832. https://doi.org/10.1001/jama.278. 10.823.

Richardson, H. A., Simmering, M. J., \& Sturman, M. C. (2009). A tale of three perspectives: Examining post hoc statistical techniques for detection and correction of common method variance. Organizational Research Methods, 12(4), 762-800. https://doi.org/10.1177/ 1094428109332834.

Roche, K. M., Mekos, D., Alexander, C. S., Astone, N. M., BandeenRoche, K., \& Ensminger, M. E. (2005). Parenting influences on early sex initiation among adolescents: How neighborhood matters. Journal of Family Issues, 26(1), 32-54. https://doi.org/10.1177/ $0192513 X 04265943$.

Russell, K., Rasmussen, S., \& Hunter, S. C. (2018). Insomnia and nightmares as markers of risk for suicidal ideation in young people: Investigating the role of defeat and entrapment. Journal of Clinical Sleep Medicine, 14(5), 775-784. https://doi.org/10.5664/jcsm. 7104. 
Sabey, A. K., Rauer, A. J., Haselschwerdt, M. L., \& Volling, B. (2018). Beyond "lots of hugs and kisses": Expressions of parental love from parents and their young children in two-parent, financially stable families. Family Process, 57(3), 737-751. https://doi.org/ 10.1111/famp.12327.

Shneyderman, Y., \& Schwartz, S. J. (2013). Contextual and intrapersonal predictors of adolescent risky sexual behavior and outcomes. Health Education and Behavior, 40(4), 400-414. https://doi.org/ 10.1177/1090198112447800.

Strassberg, D. S., McKinnon, R. K., Sustaíta, M. A., \& Rullo, J. (2013). Sexting by high school students: An exploratory and descriptive study. Archives of Sexual Behavior, 42(1), 15-21. https://doi.org/ 10.1007/s10508-012-9969-8.

Stride C. B., Gardner S., Catley, N., \& Thomas, F. (2015). Mplus code for mediation, moderation, and moderated mediation models. http://www.offbeat.group.shef.ac.uk/FIO/mplusmedmod.htm

Van Ouytsel, J., Van Gool, E., Ponnet, K., \& Walrave, M. (2014). Brief report: The association between adolescents' characteristics and engagement in sexting. Journal of Adolescence, 37(8), 1387-1391. https://doi.org/10.1016/j.adolescence.2014.10.004.

Van Ouytsel, J., Van Gool, E., Walrave, M., Ponnet, K., \& Peeters, E. (2017). Sexting: Adolescents perception of the applications used for, motives for, and consequences of sexting. Journal of Youth
Studies, 20(4), 446-470. https://doi.org/10.1080/13676261.2016. 1241865.

Villacampa, C. (2017). Teen sexting: Prevalence, characteristics and legal treatment. International Journal of Law, Crime and Justice, 49, 10-21. https://doi.org/10.1016/j.ijlcj.2017.01.002.

Walker, S., Sanci, L., \& Temple-Smith, M. (2013). Sexting: Young women's and men's views on its nature and origins. Journal of Adolescent Health, 52(6), 697-701. https://doi.org/10.1016/j.jadoh ealth.2013.01.026.

Walrave, M., Heirman, W., \& Hallam, L. (2014). Under pressure to sext? Applying the theory of planned behaviour to adolescent sexting. Behaviour and Information Technology, 33(1), 86-98. https://doi. org/10.1080/0144929X.2013.837099.

Williams, L. R., \& Anthony, E. K. (2015). A model of positive family and peer relationships on adolescent functioning. Journal of Child and Family Studies, 24(3), 658-667. https://doi.org/10.1007/ s10826-013-9876-1.

Publisher's Note Springer Nature remains neutral with regard to jurisdictional claims in published maps and institutional affiliations. 